\title{
Anatomical characteristics of mandibular bone in skeletal class I, II and III patients by using cone beam computed tomography images in an iranian population
}

Características anatômicas do osso mandibular em pacientes Classe I, II e III esquelética usando imagens de Tomografia Computadorizada de Feixe Cônico: em uma População Iraniana

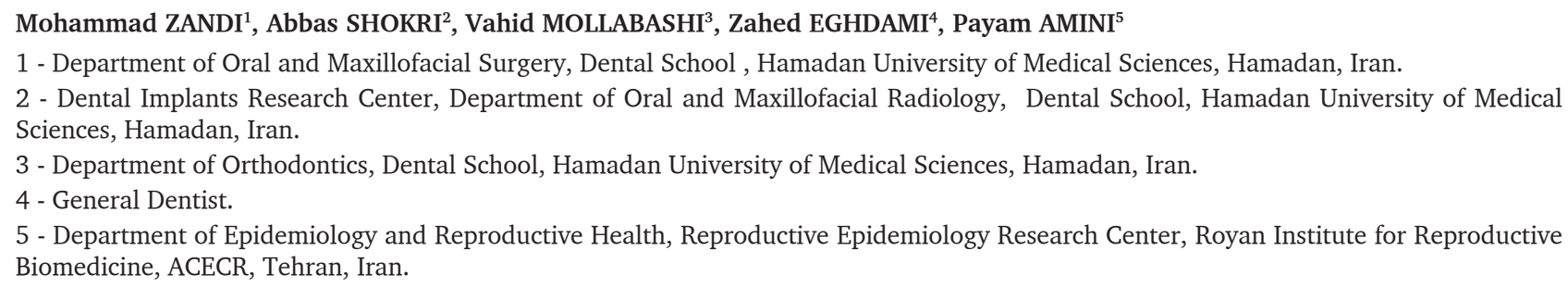

\section{ABSTRACT}

Objetive: This study aimed to compare the anatomical characteristics of the mandible in patients with skeletal class I, II and class III disorders using cone beam computed tomography (CBCT). Material and Methods: CBCT scans of patients between 17 to 40 years taken with NewTom 3G CBCT system with 12-inch field of view (FOV) were selected from the archive. Lateral cephalograms were obtained from CBCT scans of patients, and type of skeletal malocclusion was determined (Class I, II or III). All CBCT scans were evaluated in the sagittal, coronal and axial planes using the N.N.T viewer software. Results: The ramus height and distance from the mandibular foramen to the sigmoid notch in class II patients were significantly different from those in skeletal class I $(\mathrm{P}<0.005)$. Distance from the mandibular canal to the anterior border of ramus in class III individuals was significantly different from that in skeletal class I individuals $(\mathrm{P}<.005)$. Conclusion: Length of the body of mandible in skeletal class I was significantly different from that in skeletal class II and III patients. Also, ramus height in skeletal class I was significantly different from that in skeletal class II patients. CBCT had high efficacy for accurate identification of anatomical landmarks.

\section{KEYWORDS}

Prognathism; Retrognathism; Mandible; Anatomy; Cone beam computed tomography.

\section{RESUMO}

Objetivo: Este estudo teve como objetivo comparar as características anatômicas da mandíbula em pacientes com desordem esquelética Classe I, II e III usando imagens de tomografia computadorizada de feixe cônico (TCFC). Material e Métodos: Foram selecionadas de arquivo, imagens de TCFC (Sistema NewTon 3G) com FOV (campo de visão) 12 polegadas e incluindo pacientes entre 17 a 40 anos. Cefalometrias laterais foram obtidas a partir das imagens de TCFC e o tipo de maloclusão esquelética foi determinada (Classe I, II ou III). Todas as imagens de TCFC foram avaliadas nos planos sagital, coronal e axial usando o software de visualização N.N.T. Resultados: A altura do ramo e distância do forame mandibular para a incisura da mandíbula em pacientes Classe II foi significativamente diferente daqueles Classe I esquelética $(\mathrm{p}<0.005)$. A distância do canal mandibular até a borda anterior do ramo em indivíduos Classe III foi significativamente diferente daqueles indivíduos Classe I esquelética $(\mathrm{p}<0.005)$. Conclusão: $\mathrm{O}$ comprimento do corpo da mandíbula na Classe I esquelética foi diferente significativamente daqueles pacientes em Classe II e III esquelética. Além disso, a altura do ramo na Classe I esquelética foi significativamente diferente daqueles pacientes Classe II esquelética. A TCFC apresentou alta eficácia para a identificação precisa de marcos anatômicos.

\section{PALAVRAS-CHAVE}

Anatomia; Mandíbula; Prognatismo; Retrognatismo; Tomografia computadorizada de feixe cônico. 


\section{INTRODUCTION}

$\mathrm{P}$ rognathism and retrognathism of mandible are among the most common dentofacial deformities caused by over/insufficient growth of the mandible [1]. Prior to any surgical procedure, surgeons needs an adequate knowledge about the anatomy of region to minimize the undesirable surgical complications.

Aside from the inter-individual anatomical differences, maxillofacial skeletal disorders change the anatomy of mandible and its indices. For instance, the mandible body length, ramus height decrease and the gonial angle increases in patients with skeletal class II malocclusion compared to skeletal class I . In skeletal class III patients, the mandible body length and size of gonial angle increase while the ramus height decreases compared to the skeletal class I patients [2].

Since the surgical techniques are designed according to the normal anatomy of mandible, location of anatomical landmarks such as nerve position within bone, location of mental and mandibular foramina and bone thickness may vary in skeletal class II and III patients and affect the treatment outcome. Thus, such evaluations are important to increase the clinician's knowledge about the respective area anatomy.

Radiography is routinely performed to determine the skeletal dimensions. Several imaging modalities are used for this purpose and panoramic radiography and cone beam computed tomography (СВCT) are among the most commonly used techniques.

CT was introduced in 1972 and quickly gained popularity for orthodontic diagnosis and treatment planning; However, conventional CT has shortcomings such as high cost and relatively high patient radiation dose [3,4] CBCT was introduced for dentistry in 1988, and it is currently an ideal imaging modality for many dental applications.
This modality has superiority over conventional CT mainly owing to having a lower patient radiation dose, lower cost and higher spatial resolution. however conventional CT is better for the assessment of soft tissues. CBCT also enables reconstruction of two-dimensional (2D) views from three-dimensional (3D) images for conventional cephalometric analysis [5].

In CBCT, X-ray beam and the area detector rotate around the patient's head by $180^{\circ}$. During the rotation, numerous exposures are made with fixed intervals, yielding individual images known as basic images, which are similar to lateral cephalograms. Each image has a small angle relative to the initiation point. Complete series of basic images are known as projection data [6]. Software programs with complex algorithms including the back filtered projection are used for data projection to produce a series of volumetric three-dimensional data to be used for primary image reconstruction in axial, sagittal and coronal planes [6]. CBCT has advantages over medical CT for maxillofacial imaging such as variable field of view (FOV), high speed of scanning, very high resolution, lower patient radiation dose, isotropic voxels, fast analysis and enhancement of images $[7,8]$.

\section{Objectives}

Surgical techniques have been designed according to the normal anatomy of mandible; thus, in different malocclusion, location of anatomical landmarks such as nerve position within bone, location of mental and mandibular foramina and thickness of bone may vary and knowing the anatomical characteristics improve surgical outcomes. Thus, it is important to study the anatomy of this region. Textbooks only describe anatomical information of normal regions with no disorders. Considering the fact that jaw osteotomies are mainly performed on patients with jaw disorders, study of the jaw anatomy in patients with skeletal jaw disorders is imperative to provide surgeons with 
comprehensive information and decrease surgical complications.

\section{MATERIALS AND METHODS}

All experimental protocols are approved by the medical ethics committee of Hamadan University of Hamadan University of Medical Sciences (ethical approval code: IR.UMSHA. REC.1394.394).

In this study, CBCT scans were performed with NewTom 3G CBCT system (Verona, Italy) were retrieved from the CBCT archives of the Radiology Department of School of Dentistry, Hamadan University of Medical Sciences. The CBCT scans belonged to patients between 17 and 40 years old. Scans with poor quality, those belonging to patients with a history of trauma, orthognathic surgery, bone reconstruction surgery, pathologic lesions and congenital deformities were excluded. Lateral cephalograms were obtained from CBCT scans of patients and skeletal malocclusion class was determined (class I, II or III). The ANB and SNB angles were used. Patients with $0 \leq \mathrm{ANB} \leq 4$ and $78 \leq \mathrm{SNB} \leq 82$ were classified as class I, those with ANB $>4$ and SNB $<78$ were classified as class II and those with ANB $<0$ and SNB $>82$ were classified as class III [9].

After analysis of cephalometric images, 66 CBCT scans, including 34 CBCT scans of skeletal class I malocclusion , 16 CBCT scans of patients with class II malocclusion and 16 CBCT scans of class III patients were selected and included. In classification of patients, only mandibular disorders were considered. All CBCT images were evaluated in the sagittal, coronal and axial planes using NNT Viewer software (NewTom, Verona, Italy). The slice thickness was $0.5 \mathrm{~mm}$ with 1.0 $\mathrm{mm}$ intervals. The following parameters were evaluated on CBCT scans of patients:

To determine the location of mental foramen on sagittal sections, the distance from the center of mental foramen to the most inferior point in the lower border of mandible was measured. Next, the distance between the center of mental foramen and the alveolar crest was measured on the buccal surface [9]. The sum of both distances was considered as the of mandible body length in the premolar region (Figure 1a). To determine the anterior-posterior position of mental foramen in the sagittal plane, a line was drawn perpendicular to the inferior border of mandible passing through the center of mental foramen, and its horizontal distance from the apex of second premolar tooth was measured (Figure 1b).
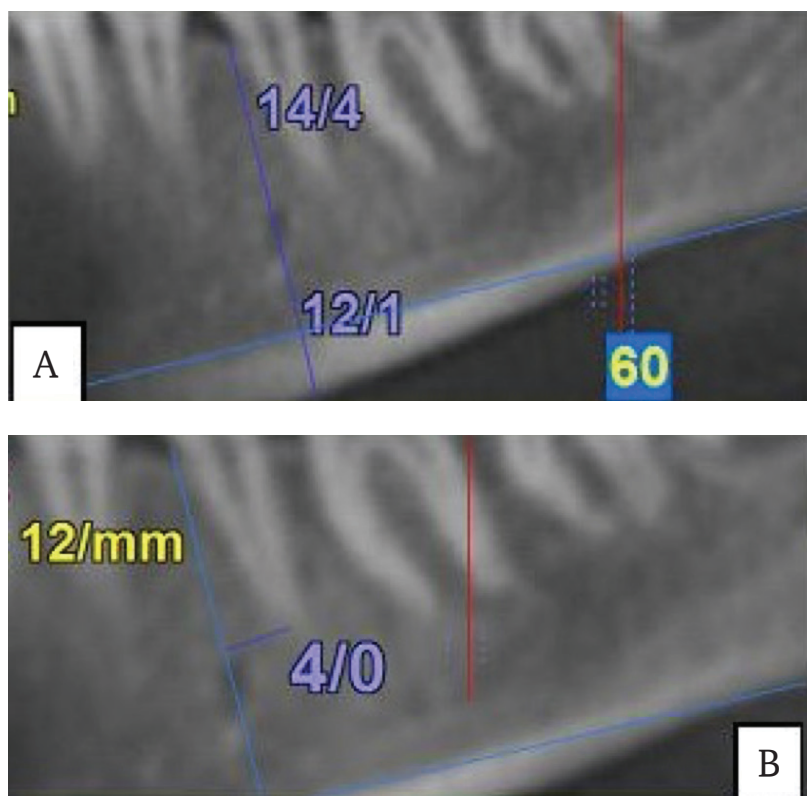

Figure 1 - Distance from the mental foramen to the alveolar crest and inferior border of the mandible (a), distance from the mental foramen to the apex of second premolar tooth (b).

To determine the anterior-posterior position of canal in the ramus area on sagittal sections, a horizontal line was drawn perpendicular to longitudinal axis of the ramus $1 \mathrm{~cm}$ below the lingula and the distance from the canal center to each of anterior and posterior borders of the ramus was measured. The sum of these two distances indicated the anterior-posterior width of ramus (Figure 2a). 
To determine the medio-lateral position of canal at the ramus area on coronal sections, the distance from canal center to each of medial and lateral cortices of ramus was measured as $1 \mathrm{~cm}$ below the superior border of mandibular foramen. The sum of these two distances indicated mediolateral width of ramus (Figure $2 \mathrm{~b}$ ).

To determine the superior-inferior position of canal at first molar area on sagittal sections, a line was drawn from the center of first molar furcation area perpendicular to the inferior border of mandible and then the distance from the canal center to alveolar crest and inferior border of mandible body was measured along the afore-mentioned line. The sum of both distances indicated the mandibular length at first molar area (Figure 2c).
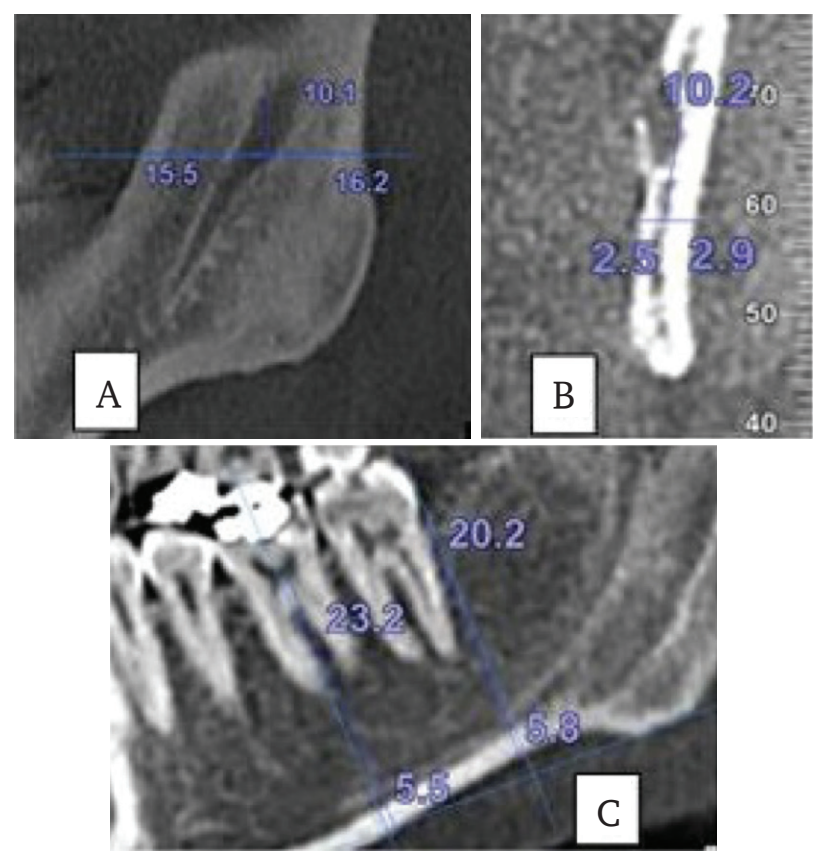

Figure 2 - Distance from the mandibular canal to the anterior and posterior borders of ramus (a), distance from the mandibular canal to the medial and lateral cortices of ramus (b) and distance from the mandibular canal to the alveolar crest and inferior border of the mandible at the first molar furcation site and distal to the second molar (c).
To determine the buccolingual position of canal at first molar area in the coronal plane, a section passing through the furcation area of first molar tooth was chosen and the distance from the canal center at first molar site to each of buccal and lingual cortices of mandible body was measured. The sum of these two distances indicated the buccolingual thickness of mandible at first molar site (Figure 3a).

To determine the superior-inferior position of canal at second molar area in the sagittal plane, a line was drawn distal to the second molar tooth perpendicular to inferior border of mandible. The distance from canal center to alveolar crest and inferior border of mandible was measured along this line. The sum of both distances indicated the mandibular body length at second molar area (Figure 2c).

To determine the buccolingual position of canal at site of second molar in the coronal plane, an image was chosen that passed the alveolar crest distal to the second molar. The distance from canal center in this region to each of buccal and lingual cortices of mandible body was measured. The sum of these two distances served as buccolingual thickness of mandible at the site of second molar tooth (Figure $3 \mathrm{~b}$ ).
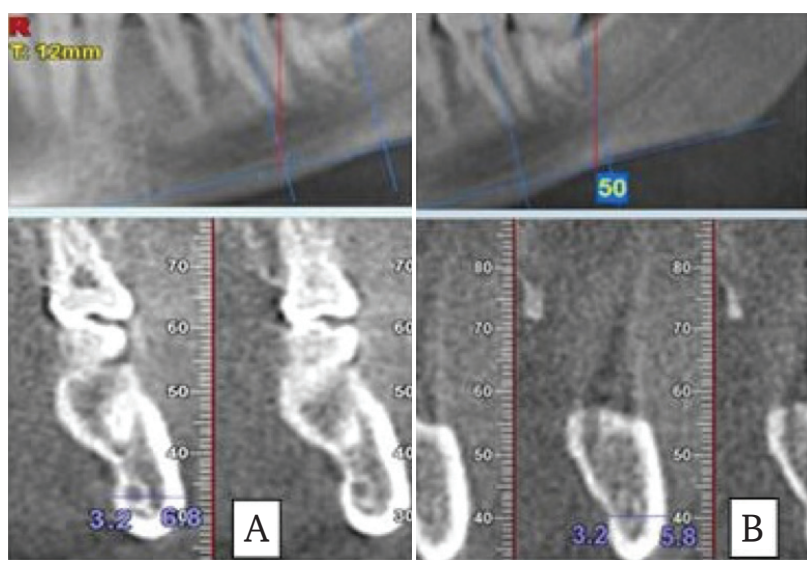

Figure 3 - Distance from the mandibular canal to the buccal and lingual cortices of the mandible at the first molar furcation site (a) and distance from the mandibular canal to the buccal and lingual cortices of the mandible distal to the second molar tooth (b). 
To determine the anterior-posterior position of mandibular foramen in the sagittal plane, a horizontal line was drawn from the lingula perpendicular to longitudinal axis of mandibular ramus. Next, another horizontal line was drawn parallel at $5 \mathrm{~mm}$ below the previous line. Between these two lines, the distance from mandibular foramen center to each of anterior and posterior borders of ramus was measured. The sum of these two distances was considered as anterior-posterior width of ramus at site of mandibular foramen (Figure 4a).

We could not obtain an image completely visualizing the ramus. Thus, to determine the superior-inferior position of mandibular foramen in the sagittal plane, we used an image showing the condyle and sigmoid notch and identified the deepest point of sigmoid notch (Figure 4b). Next, from the superior border of mandibular foramen, a horizontal line was drawn perpendicular to the longitudinal axis of mandibular ramus and then another horizontal line was drawn parallel and $5 \mathrm{~mm}$ below the previous line. We then measured the distance from deepest point of sigmoid notch to midline of these two lines and its continuation to inferior border of mandible. The sum of these two distances served as the ramus height [5] (Figure 4c).

To measure the mandible length, first Gonion (Go) point was identified. Go is located on the curvature of mandible angle. To identify this point, we drew an angle at the intersection of posterior border of ramus and inferior border of mandible. The point at which the bisect of this angle cut the inferior border of mandible was identified as Go. Next, the distance from Go to Pogonion (most anterior point of chin) was measured and considered as the mandible body length [10] (Figure 4d).

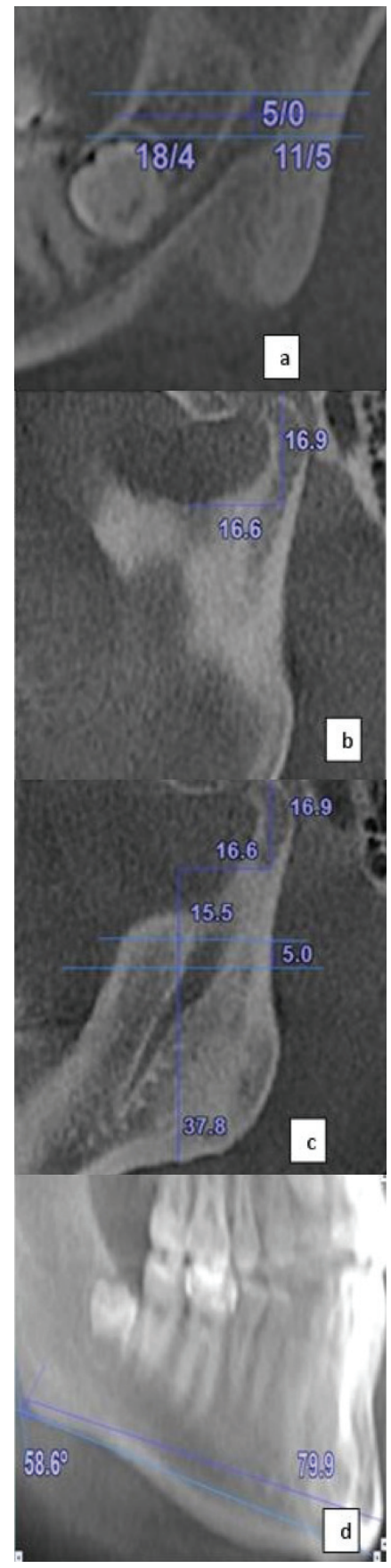

Figure 4 - Distance from the mandibular foramen to the anterior and posterior borders of ramus (a), location of sigmoid notch (b), distance from the mandibular foramen to the sigmoid notch and inferior border of the mandible (c) and length of the body of mandible (d).

All measurements were made in duplicate by an oral and maxillofacial radiologist and a maxillofacial surgeon that well-trained to work with NNT Viewer software. By changing 
the contrast, brightness and magnification, images with maximum clarity were obtained for identification of anatomical landmarks. Data were analyzed using SPSS version 16. Significance level was set at $\leq 0.05$. The Cronbach's alpha was applied to assess the reliability of measurements.

\section{RESULTS}

To assess the intra- and inter-observer reliability, the Cronbach's alpha was calculated, which showed $86 \%$ and $92 \%$ as inter-observer and intra-observer agreement, respectively. Comparison between the mental foramen position in three skeletal groups (Table I) showed that class III skeletal pattern had greatest mean distance from mental foramen to alveolar crest, inferior border of mandible and apex of second premolar tooth and highest mean of mandible length at the premolar region. ANOVA showed no significant difference among the three groups in any of four variables evaluated ( $\mathrm{p} \leq 0.05)$.

Table I - Comparison of the mental foramen position in the three skeletal groups

\begin{tabular}{|c|c|c|c|c|c|c|c|}
\hline & $\begin{array}{c}\text { skeletal } \\
\text { class } \\
\text { |/ II/III }\end{array}$ & $\mathbf{N}$ & $\begin{array}{l}\text { Mean } \\
(\mathrm{mm})\end{array}$ & $\begin{array}{c}\text { Std. } \\
\text { Devia- } \\
\text { tion }\end{array}$ & $\underset{(\mathrm{mm})}{\operatorname{Minimum}}$ & $\begin{array}{l}\text { Maxi- } \\
\text { mum } \\
(\mathrm{mm})\end{array}$ & $\begin{array}{c}P \\
\text { value }\end{array}$ \\
\hline \multirow{4}{*}{ MEFC' } & 1 & 34 & 17.750 & 2.9208 & 10.7 & 23.5 & \multirow{4}{*}{.975} \\
\hline & 2 & 16 & 17.625 & 2.4485 & 13.8 & 226 & \\
\hline & 3 & 16 & 17850 & 3.0327 & 14.1 & 24.1 & \\
\hline & Total & 66 & 17.744 & 28006 & 10.7 & 24.1 & \\
\hline \multirow{4}{*}{ MEFFi } & 1 & 34 & 12.944 & 2.0328 & 9.3 & 17.2 & \multirow{4}{*}{.672} \\
\hline & 2 & 16 & 12.663 & 1.9883 & 10.1 & 17.7 & \\
\hline & 3 & 16 & 13.281 & 1.7574 & 9.5 & 16.0 & \\
\hline & Total & 66 & 12.958 & 1.9417 & 9.3 & 17.7 & \\
\hline \multirow{4}{*}{$\begin{array}{l}\text { Premolar } \\
\text { height }\end{array}$} & 1 & 34 & 30.4059 & 2.93526 & 25.20 & 36.10 & \multirow{4}{*}{.724} \\
\hline & 2 & 16 & 29.7188 & 3.74935 & 23.70 & 38.10 & \\
\hline & 3 & 16 & 30.5063 & 287599 & 23.70 & 36.40 & \\
\hline & Total & 66 & 30.2636 & 3.10244 & 23.70 & 38.10 & \\
\hline \multirow{4}{*}{$\mathrm{MEFa}^{3}$} & 1 & 34 & 4.068 & 1.8816 & 1.1 & 8.0 & \multirow{4}{*}{.100} \\
\hline & 2 & 16 & 4.350 & 25882 & .0 & 8.9 & \\
\hline & 3 & 16 & 5.406 & 1.6905 & 1.8 & 7.8 & \\
\hline & Total & 66 & 4.461 & 2.0753 & .0 & 8.9 & \\
\hline
\end{tabular}

1.MEFc: Distance from mental foramen to crest.

2.MEFi: Distance from mental foramen to inferior border.

3.MEFa: Distance from mental foramen to apex of second pm.

As shown in Table II, three skeletal groups were not significantly different in the mean distance from the mandibular canal to alveolar crest and inferior border at the site of first molar furcation and distal of second molar tooth ( $\mathrm{p} \leq 0.05$ ). The lowest mean length of mandible at the site of first molar furcation area and distal of second molar tooth was noted in skeletal class II patients but ANOVA showed no significant difference in this respect among the three groups ( $\mathrm{p} \leq 0.05)$. The highest mean distance from the mandibular canal to posterior border of ramus belonged to skeletal class III patients and lowest mean width of ramus was noted in skeletal class II patients but the difference among three groups was not significant in any of two above-mentioned variables (Table II).

Table II - Comparison of the mandibular canal position in the three skeletal groups

\begin{tabular}{|c|c|c|c|c|c|c|c|}
\hline & $\begin{array}{c}\text { skeletal } \\
\text { class } \\
\text { |/ || /|| }\end{array}$ & $\mathbf{N}$ & $\begin{array}{l}\text { Mean } \\
(\mathrm{mm})\end{array}$ & $\begin{array}{l}\text { Std. } \\
\text { Devia- } \\
\text { tion }\end{array}$ & $\begin{array}{l}\text { Minimum } \\
\text { (mm) }\end{array}$ & $\begin{array}{l}\text { Maxi- } \\
\text { mum } \\
(\mathrm{mm})\end{array}$ & $\begin{array}{c}P \\
\text { value }\end{array}$ \\
\hline \multirow{4}{*}{ MCc1 1} & 1 & 34 & 19.921 & 2.6828 & 15.5 & 25.6 & \multirow{4}{*}{.708} \\
\hline & 2 & 16 & 19.281 & 2.9757 & 14.9 & 25.4 & \\
\hline & 3 & 16 & 20.144 & 3.9443 & 12.4 & 28.7 & \\
\hline & Total & 66 & 19.820 & 3.0643 & 12.4 & 28.7 & \\
\hline \multirow{4}{*}{$\mathrm{MCi}^{2}$} & 1 & 34 & 6.992 & 1.8413 & 4.3 & 12.7 & \multirow{4}{*}{.906} \\
\hline & 2 & 16 & 7.194 & 1.4762 & 5.5 & 10.7 & \\
\hline & 3 & 16 & 6.937 & 1.8622 & 4.3 & 10.7 & \\
\hline & Total & 66 & 7.028 & 1.7418 & 4.3 & 12.7 & \\
\hline \multirow{4}{*}{$\begin{array}{l}\text { molar1 } \\
\text { height }^{3}\end{array}$} & 1 & 34 & 26.8529 & 2.79428 & 21.00 & 33.80 & \multirow{4}{*}{.831} \\
\hline & 2 & 16 & 26.4750 & 2.78891 & 22.20 & 33.50 & \\
\hline & 3 & 16 & 27.0812 & 3.03869 & 19.30 & 33.50 & \\
\hline & Total & 66 & 26.8167 & 2.81718 & 19.30 & 33.80 & \\
\hline \multirow{4}{*}{$\mathrm{MCC}^{4}$} & 1 & 34 & 16.347 & 2.4562 & 10.0 & 21.4 & \multirow{4}{*}{.609} \\
\hline & 2 & 16 & 15.844 & 2.4000 & 11.7 & 20.2 & \\
\hline & 3 & 16 & 15.550 & 3.6253 & 10.3 & 25.9 & \\
\hline & Total & 66 & 16.032 & 2.7464 & 10.0 & 25.9 & \\
\hline \multirow{4}{*}{$\mathrm{MCi}^{5}$} & 1 & 34 & 7.385 & 2.1511 & 4.5 & 14.5 & \multirow{4}{*}{.206} \\
\hline & 2 & 16 & 6.388 & 1.4023 & 4.2 & 9.8 & \\
\hline & 3 & 16 & 7.419 & 1.9563 & 3.2 & 10.5 & \\
\hline & Total & 66 & 7.152 & 1.9688 & 3.2 & 14.5 & \\
\hline \multirow{4}{*}{$\begin{array}{l}\text { molar2 } \\
\text { height }^{6}\end{array}$} & 1 & 34 & 23.7294 & 3.16099 & 14.80 & 29.20 & \multirow{4}{*}{.254} \\
\hline & 2 & 16 & 22.2313 & 2.66676 & 18.30 & 27.20 & \\
\hline & 3 & 16 & 22.9688 & 2.99282 & 16.30 & 29.10 & \\
\hline & Total & 66 & 23.1818 & 3.02842 & 14.80 & 29.20 & \\
\hline \multirow{4}{*}{$\mathrm{MCa}^{7}$} & 1 & 34 & 15.021 & 21105 & 9.7 & 19.1 & \multirow{4}{*}{.035} \\
\hline & 2 & 16 & 13.944 & 1.6440 & 11.5 & 16.6 & \\
\hline & 3 & 16 & 13.619 & 1.7471 & 10.4 & 18.1 & \\
\hline & Total & 66 & 14.420 & 1.9980 & 9.7 & 19.1 & \\
\hline \multirow{4}{*}{$M C p^{8}$} & 1 & 34 & 15.497 & 2.8585 & 9.4 & 22.3 & \multirow{4}{*}{.596} \\
\hline & 2 & 16 & 15.013 & 2.0523 & 11.2 & 18.4 & \\
\hline & 3 & 16 & 15.975 & 2.7726 & 10.1 & 20.5 & \\
\hline & Total & 66 & 15.495 & 2.6473 & 9.4 & 22.3 & \\
\hline \multirow{4}{*}{$\begin{array}{l}\text { Ramus } \\
\text { width }\end{array}$} & 1 & 34 & 30.5176 & 3.70630 & 22.70 & 38.10 & \multirow{4}{*}{.260} \\
\hline & 2 & 16 & 28.9562 & 2.49639 & 26.00 & 34.60 & \\
\hline & 3 & 16 & 29.5937 & 2.71894 & 24.10 & 35.60 & \\
\hline & Total & 66 & 29.9152 & 3.24958 & 22.70 & 38.10 & \\
\hline
\end{tabular}

1.MCc1: Distance from mandibular canal to crest in first molar. 2.MCi1: Distance from mandibular canal to inferior border in first molar. 3.Height of mandible in first molar. 4.MCc2: Distance from mandibular canal to crest in distal second molar. 5.MCi2: Distance from mandibular canal to inferior border in distal second molar. 6. Height of mandible in distal second molar. 7.MCa: Distance from mandibular canal to anterior border of ramus. 8.MCp: Distance from mandibular canal to posterior border of ramus. 
The greatest mean distance from canal to anterior border of ramus was noted in skeletal class I patients and lowest mean was noted in skeletal class III patients. The results of ANOVA showed a significant difference among three groups in the distance from mandibular canal to the anterior border of ramus $(P=0.035)$. LSD test showed that skeletal class I and III patients were different in this respect (Table III).

Table III - Results of ANOVA test regarding distance from the mandibular canal to the anterior border of ramus in the three groups

\begin{tabular}{|c|c|c|c|c|c|c|}
\hline $\begin{array}{c}\text { (I) } \\
\text { occlusion }\end{array}$ & $\begin{array}{c}\text { (J) } \\
\text { occlusion }\end{array}$ & $\begin{array}{c}\text { Mean } \\
\text { Difference } \\
(1-J)\end{array}$ & Std. Error & Sig. & $\begin{array}{l}\text { Lower } \\
\text { Bound }\end{array}$ & $\begin{array}{l}\text { Upper } \\
\text { Bound }\end{array}$ \\
\hline \multirow{2}{*}{1} & 2 & 1.0768 & .5834 & .070 & -.089 & 2.243 \\
\hline & 3 & $1.4018^{\star}$ & .5834 & .019 & .236 & 2.568 \\
\hline \multirow{2}{*}{2} & 1 & -1.0768 & .5834 & .070 & -2.243 & .089 \\
\hline & 3 & .3250 & .6804 & .635 & -1.035 & 1.685 \\
\hline & 1 & $-1.4018^{*}$ & .5834 & .019 & -2.568 & -.236 \\
\hline & 2 & -3250 & .6804 & .635 & -1.685 & 1.035 \\
\hline
\end{tabular}

*The mean difference is significant at the 0.05 level.

Comparison between the mean thickness of mandible in the three skeletal groups (Table IV) showed that skeletal class II patients had lowest mean distance from mandibular canal to lingual cortex and lowest mean buccolingual thickness of mandible at the furcation site of first molar and distal of second molar. The greatest buccolingual thickness mean of mandible belonged to class III skeletal patients. Despite these differences, ANOVA showed no significant difference in the afore-mentioned variables among the three groups ( $\mathrm{p} \leq 0.05$ ).

Skeletal class III patients had the lowest mean distance from the mandibular canal to the internal and external borders of ramus and the lowest mean ramus width at the mandibular canal site (Table IV) but the difference among three groups was not significant in any of three above-mentioned variables ( $\mathrm{p} \leq 0.05$ ).
Table IV - Comparison of the mean thickness of the mandible in the three skeletal groups

\begin{tabular}{|c|c|c|c|c|c|c|c|}
\hline & $\begin{array}{c}\text { skeletal } \\
\text { class } \\
\text { //II/II }\end{array}$ & N & $\begin{array}{l}\text { Mean } \\
(\mathrm{mm})\end{array}$ & $\begin{array}{l}\text { Std. } \\
\text { Devia- } \\
\text { tion }\end{array}$ & $\begin{array}{c}\text { Minimum } \\
(\mathrm{mm})\end{array}$ & $\begin{array}{l}\text { Maxi- } \\
\text { mum } \\
(\mathrm{mm})\end{array}$ & $\begin{array}{c}P \\
\text { value }\end{array}$ \\
\hline \multirow{4}{*}{$\mathrm{LT}^{1}{ }^{1}$} & 1 & 34 & 3.712 & .9088 & 2.2 & 6.5 & \multirow{4}{*}{.756} \\
\hline & 2 & 16 & 3.488 & .8663 & 2.2 & 5.0 & \\
\hline & 3 & 16 & 3.631 & 1.2365 & 1.7 & 7.2 & \\
\hline & Total & 66 & 3.638 & .9766 & 1.7 & 7.2 & \\
\hline \multirow{4}{*}{$\mathrm{BT}^{2}$} & 1 & 34 & 5.953 & 1.3083 & 2.9 & 8.3 & \multirow{4}{*}{.846} \\
\hline & 2 & 16 & 5.962 & 1.0732 & 4.3 & 8.6 & \\
\hline & 3 & 16 & 6.156 & 1.0918 & 4.6 & 7.9 & \\
\hline & Total & 66 & 6.005 & 1.1905 & 2.9 & 8.6 & \\
\hline \multirow{4}{*}{$\mathrm{BLT}^{3}$} & 1 & 34 & 9.6647 & 1.34003 & 7.10 & 13.00 & \multirow{4}{*}{.796} \\
\hline & 2 & 16 & 9.4500 & .89963 & 7.50 & 10.80 & \\
\hline & 3 & 16 & 9.7813 & 1.91249 & 7.10 & 15.10 & \\
\hline & Total & 66 & 9.6409 & 1.39879 & 7.10 & 15.10 & \\
\hline \multirow{4}{*}{ LT2 $^{4}$} & 1 & 34 & 4.309 & 1.3116 & 2.2 & 9.0 & \multirow{4}{*}{.166} \\
\hline & 2 & 16 & 3.544 & 1.0315 & 2.2 & 5.5 & \\
\hline & 3 & 16 & 4.187 & 1.6145 & 2.3 & 8.3 & \\
\hline & Total & 66 & 4.094 & 1.3495 & 2.2 & 9.0 & \\
\hline \multirow{4}{*}{$\mathrm{BT}^{5}$} & 1 & 34 & 5.447 & 1.4515 & 2.9 & 9.0 & \multirow{4}{*}{.246} \\
\hline & 2 & 16 & 5.925 & 1.2850 & 4.2 & 8.6 & \\
\hline & 3 & 16 & 6.094 & 1.2943 & 4.0 & 8.6 & \\
\hline & Total & 66 & 5.720 & 1.3860 & 2.9 & 9.0 & \\
\hline \multirow{4}{*}{ BLT2 $^{6}$} & 1 & 34 & 9.7559 & 1.88216 & 5.10 & 14.10 & \multirow{4}{*}{.488} \\
\hline & 2 & 16 & 9.4688 & 1.48176 & 6.70 & 11.50 & \\
\hline & 3 & 16 & 10.2813 & 2.44355 & 6.90 & 16.90 & \\
\hline & Total & 66 & 9.8136 & 1.94112 & 5.10 & 16.90 & \\
\hline \multirow{4}{*}{ MT } & 1 & 34 & 2.747 & .6161 & 1.4 & 4.0 & \multirow{4}{*}{.578} \\
\hline & 2 & 16 & 2.594 & .5531 & 1.8 & 3.6 & \\
\hline & 3 & 16 & 2.575 & .7262 & 1.3 & 4.0 & \\
\hline & Total & 66 & 2.668 & .6259 & 1.3 & 4.0 & \\
\hline \multirow{4}{*}{$\mathrm{LT}^{8}$} & 1 & 34 & 3.176 & .8804 & 1.7 & 5.9 & \multirow{4}{*}{.836} \\
\hline & 2 & 16 & 3.144 & .6562 & 1.8 & 4.3 & \\
\hline & 3 & 16 & 3.038 & .5875 & 2.1 & 4.0 & \\
\hline & Total & 66 & 3.135 & .7588 & 1.7 & 5.9 & \\
\hline \multirow{4}{*}{$\begin{array}{l}\text { Ramus } \\
\text { thick- } \\
\text { ness }\end{array}$} & 1 & 34 & 5.8059 & 1.21778 & 3.20 & 9.00 & \multirow{4}{*}{.867} \\
\hline & 2 & 16 & 5.7375 & 1.13189 & 3.60 & 7.90 & \\
\hline & 3 & 16 & 5.6125 & 1.19436 & 3.80 & 7.60 & \\
\hline & Total & 66 & 5.7424 & 1.17644 & 3.20 & 9.00 & \\
\hline
\end{tabular}

1.LT1: Lingual thickness in first molar 2.BT1: Buccal thickness in first molar 3.BLT1: Buccolingual thickness in firstmolar 4.LT2: Lingual thickness in distal second molar 5.BT2: Buccal thickness in distal second molar 6.BLT2: Buccolingual thickness in distal second molar 7. MT: Medial ramus thickness

8. LT: Lateral ramus thickness 
Skeletal class II patients showed lowest mean distance from the mandibular foramen to anterior and posterior borders of ramus and lowest mean width of ramus at mandibular foramen site but the difference among three groups was not significant in any of three abovementioned variables $(\mathrm{p} \leq 0.05)$ (Table V).

Table V - Comparison of the mean position from the mandibular foramen in the three skeletal groups

\begin{tabular}{|c|c|c|c|c|c|c|c|}
\hline & $\begin{array}{c}\text { skeletal } \\
\text { class } \\
\text { |/ II/III }\end{array}$ & N & $\begin{array}{l}\text { Mean } \\
(\mathrm{mm})\end{array}$ & $\begin{array}{l}\text { Std. } \\
\text { Devia- } \\
\text { tion }\end{array}$ & $\begin{array}{c}\text { Minimum } \\
(\mathrm{mm})\end{array}$ & $\begin{array}{l}\text { Maxi- } \\
\text { mum } \\
(\mathrm{mm})\end{array}$ & $\begin{array}{c}P \\
\text { value }\end{array}$ \\
\hline \multirow{4}{*}{$\mathrm{MAFa}^{1}$} & 1 & 34 & 15.579 & 1.7556 & 10.1 & 18.7 & \multirow{4}{*}{.188} \\
\hline & 2 & 16 & 14.638 & 2.2253 & 12.2 & 21.2 & \\
\hline & 3 & 16 & 14.931 & 1.3598 & 12.6 & 17.9 & \\
\hline & Total & 66 & 15.194 & 1.8180 & 10.1 & 21.2 & \\
\hline \multirow{4}{*}{ MAFp² } & 1 & 34 & 12.632 & 2.3529 & 7.9 & 18.4 & \multirow{4}{*}{.231} \\
\hline & 2 & 16 & 11.731 & 1.1200 & 9.4 & 13.0 & \\
\hline & 3 & 16 & 12.875 & 1.9244 & 9.7 & 15.8 & \\
\hline & Total & 66 & 12.473 & 2.0355 & 7.9 & 18.4 & \\
\hline \multirow{4}{*}{$\begin{array}{l}\text { Ramus } \\
\text { width } \\
\text { in man- } \\
\text { dibular } \\
\text { foramen }\end{array}$} & 1 & 34 & 28.2088 & 3.14752 & 20.90 & 34.60 & \multirow{4}{*}{.118} \\
\hline & 2 & 16 & 26.3688 & 2.78513 & 23.40 & 34.20 & \\
\hline & 3 & 16 & 27.6813 & 2.33559 & 23.40 & 31.60 & \\
\hline & Total & 66 & 27.6348 & 2.94041 & 20.90 & 34.60 & \\
\hline \multirow{4}{*}{$\mathrm{MAFs}^{3}$} & 1 & 34 & 19.988 & 3.0932 & 14.4 & 29.1 & \multirow{4}{*}{.021} \\
\hline & 2 & 16 & 17.438 & 1.7088 & 14.1 & 20.1 & \\
\hline & 3 & 16 & 19.500 & 3.5788 & 15.1 & 27.0 & \\
\hline & Total & 66 & 19.252 & 3.0978 & 14.1 & 29.1 & \\
\hline \multirow{4}{*}{$\mathrm{MAF}^{4}$} & 1 & 34 & 28.803 & 4.0130 & 20.1 & 37.1 & \multirow{4}{*}{.447} \\
\hline & 2 & 16 & 27.163 & 4.0332 & 22.0 & 37.8 & \\
\hline & 3 & 16 & 28.975 & 6.2267 & 15.9 & 38.9 & \\
\hline & Total & 66 & 28.447 & 4.6279 & 15.9 & 38.9 & \\
\hline
\end{tabular}

1.MAFa: Distancefrom mandibular foramen to anterior border of ramus.

2.MAFp: Distance from mandibular foramen to posterior border of ramus.

3.MANs: Distance from mandibular foramen to sigmoid notch. 4.MANi: Distance from mandibular foramen to inferior border.

Regarding the distance from the mandibular foramen to the sigmoid notch (MaFs), class I skeletal pattern showed the highest mean distance and skeletal class II patients showed the lowest mean distance among three groups. ANOVA showed that MAFs is significantly different among the three groups $(\mathrm{P}=0.021)$. LSD test revealed that class I and class II patients are different in this respect (Table VI).
Table VI - Results of ANOVA test regarding distance from the mandibular canal to the anterior border of ramus in the three groups

\begin{tabular}{|c|c|c|c|c|c|c|}
\hline $\begin{array}{c}\text { (I) } \\
\text { occlusion }\end{array}$ & $\begin{array}{c}\text { (J) } \\
\text { occlusion }\end{array}$ & $\begin{array}{c}\text { Mean } \\
\text { Difference } \\
(I-J)\end{array}$ & Std. Error & Sig. & $\begin{array}{l}\text { Lower } \\
\text { Bound }\end{array}$ & $\begin{array}{l}\text { Upper } \\
\text { Bound }\end{array}$ \\
\hline \multirow{2}{*}{1} & 2 & $2.5507^{\star}$ & .8971 & .006 & .758 & 4.343 \\
\hline & 3 & .4882 & .8971 & .588 & -1.305 & 2.281 \\
\hline \multirow{2}{*}{2} & 1 & $-2.5507^{\star}$ & .8971 & .006 & -4.343 & -.758 \\
\hline & 3 & -2.0625 & 1.0462 & .053 & -4.153 & .028 \\
\hline \multirow[t]{2}{*}{2} & 1 & -4882 & .8971 & .588 & -2.281 & 1.305 \\
\hline & 2 & 2.0625 & 1.0462 & .053 & -.028 & 4.153 \\
\hline
\end{tabular}

*The mean difference is significant at the 0.05 level.

Comparison of the mean ramus height and mandibular length among three groups showed that skeletal class I patients had greatest mean height and skeletal class II patients had lowest mean height of ramus among three groups (Table VII). ANOVA along with Dunnett's test (comparing each group with normal group) revealed that ramus height in skeletal class II patients was significantly different from that in skeletal class I patients ( $\mathrm{P}=0.007$, Table VIII). Skeletal class III patients had the highest mean length of mandible and skeletal class II patients had lowest mean length of mandible among three groups. ANOVA along with Dunnett's test revealed that mandibular length is significantly different in class I and II and also class I and III patients ( $\mathrm{P}=0.000$, Table VIII).

Table VII - Comparison the mean ramus height and mandibular length in the three skeletal groups

\begin{tabular}{|c|c|c|c|c|c|c|c|}
\hline & $\begin{array}{c}\text { skeletal } \\
\text { class } \\
\text { |/ || /III }\end{array}$ & $\mathbf{N}$ & $\begin{array}{l}\text { Mean } \\
(\mathrm{mm})\end{array}$ & $\begin{array}{l}\text { Std. } \\
\text { Devia- } \\
\text { tion }\end{array}$ & $\begin{array}{l}\text { Minimum } \\
(\mathrm{mm})\end{array}$ & $\begin{array}{l}\text { Maxi- } \\
\text { mum } \\
(\mathrm{mm})\end{array}$ & $\begin{array}{c}P \\
\text { value }\end{array}$ \\
\hline \multirow{4}{*}{$\begin{array}{l}\text { Ramus } \\
\text { height }\end{array}$} & 1 & 34 & 48.7971 & 4.29979 & 40.60 & 58.70 & \multirow{4}{*}{.007} \\
\hline & 2 & 16 & 44.6000 & 3.82379 & 39.20 & 53.30 & \\
\hline & 3 & 16 & 48.4875 & 5.00132 & 39.20 & 58.00 & \\
\hline & Total & 66 & 47.7045 & 4.65623 & 39.20 & 58.70 & \\
\hline \multirow{4}{*}{$\begin{array}{l}\text { Man- } \\
\text { dibular } \\
\text { length }\end{array}$} & 1 & 34 & 88.504 & 5.3214 & 80.9 & 103.3 & \multirow{4}{*}{.000} \\
\hline & 2 & 16 & 82.206 & 3.4048 & 75.9 & 88.8 & \\
\hline & 3 & 16 & 92.178 & 6.7139 & 77.3 & 100.3 & \\
\hline & Total & 66 & 87.868 & 6.3346 & 75.9 & 103.3 & \\
\hline
\end{tabular}


Table VIII - Results of ANOVA regarding the ramus height and length of the body of mandible in the three groups

\begin{tabular}{|ccccccccc|}
$\begin{array}{c}\text { Depen- } \\
\text { dent } \\
\text { Variable }\end{array}$ & $\begin{array}{c}\mathbf{( I )} \\
\text { occlusion }\end{array}$ & $\begin{array}{c}(\mathrm{J}) \\
\text { occlusion }\end{array}$ & $\begin{array}{c}\text { Mean } \\
\text { Difference } \\
(\mathbf{I}-\mathbf{J})\end{array}$ & $\begin{array}{c}\text { Std. } \\
\text { Error }\end{array}$ & $\begin{array}{c}\text { Sig. } \\
\text { Occower }\end{array}$ & $\begin{array}{c}\text { Upper } \\
\text { Bound } \\
\text { Bound }\end{array}$ \\
\hline $\begin{array}{l}\text { Ramus } \\
\text { height }\end{array}$ & 2 & 1 & $-4.19706^{\star}$ & 1.32569 & .005 & -7.2188 & -1.1753 \\
\hline $\begin{array}{l}\text { Mandibu- } \\
\text { lar length }\end{array}$ & 2 & 3 & 1 & -.30956 & 1.32569 & .964 & -3.3313 & 2.7122 \\
\hline
\end{tabular}

*. The mean difference is significant at the 0.05 level.

\section{DISCUSSION}

Several surgical techniques have been proposed for correction of mandibular deformities. Surgical techniques have been designed according to the normal anatomy of mandible; thus, in skeletal class II and class III patients, location of anatomical landmarks such as nerve position within bone, location of mental and mandibular foramina and thickness of bone may vary and this can affect the treatment. Thus, it is important to study the anatomy of this region.

In the current study, the mean distance from the mental foramen to the alveolar crest were $17.2 \pm 75.92 \mathrm{~mm}, 17.62 \pm 2.44 \mathrm{~mm}$ and 17.3 $\pm 85.03 \mathrm{~mm}$ in normal individuals, skeletal class II and in skeletal class III patients, respectively. Also, the mean distances from mental foramen to inferior border of mandible were $12.94 \pm 2.03$ $\mathrm{mm}, 12.66 \pm 1.98 \mathrm{~mm}$ and $13.28 \pm 1.75 \mathrm{~mm}$ in skeletal class I , class II and class III patients, respectively. In a study by Oguz et al, [11] on dry skulls of adult Turkish males, the distance from mental foramen to alveolar crest was $13.62 \mathrm{~mm}$ and the distance from mental foramen to inferior border of mandible was $14.61 \mathrm{~mm}$. In a study by Voljevica, [12] on dry skulls, the distance from mental foramen to alveolar crest was $14.37 \pm 4.3$ $\mathrm{mm}$ and the distance from the mental foramen to inferior border of mandible was $12.67 \pm 2 \mathrm{~mm}$. Alma et al, and Oguz et al. did not determine the normal position, prognathism or retrognathism of the mandible and their results might have been a combination of measurements made on the mandibles with different skeletal classes. Also, since the studies by Alma et al, and Oguz et al. were conducted on dry skulls, the difference between their values and ours may be related to bone loss and our results are probably closer to the actual values. Kane et al. [13] reported that the distance from mental foramen to inferior border of mandible was smaller in patients with mandibular prognathism compared to mandibular retrognathism; whereas, opposite results were obtained in our study and the distance from mental foramen to inferior border of mandible in patients with mandibular prognathism was greater than the patients with mandibular retrognathism but this difference was not statistically significant. In our study, CBCT was used to assess the landmarks while CT was used by Kane et al. [13]. Differences in the type of imaging technique, sample sizes, measurement methods can cause differences between the present study and the mentioned study.

In our study, the mean distance from the mandibular canal to the alveolar crest in three groups was $19.82 \pm 3.06 \mathrm{~mm}$ at furcation area of first molar tooth and $16.03 \pm 2.74 \mathrm{~mm}$ at distal of second molar tooth. Also, the mean distance from the mandibular canal to the inferior border of the mandible in three groups was $7.1 \pm 02.74$ $\mathrm{mm}$ at the furcation site of first molar and 7.15 $\pm 1.9 \mathrm{~mm}$ at distal of second molar tooth. In a study by Sekerci et al, [14] the distance from the mandibular canal to alveolar crest was $14.4 \mathrm{~mm}$ at first molar site, $10.6 \mathrm{~mm}$ at second molar site and $9.4 \mathrm{~mm}$ at third molar site. Our results and Sekerci et al. follow the anatomy of mandibular canal from the posterior to anterior region as distance from the canal to alveolar crest increases and the distance from canal to inferior border of mandible decreases towards the inferior border of mandible. Yu et al. [15] reported that the distance from mandibular canal to inferior border of mandible at first and second molar sites was smaller in patients with mandibular prognathism compared to the skeletal class I malocclusion. The 
same result was obtained in normal individuals and patients with mandibular prognathism but the difference between them was not statistically significant.

In our study, the distance from mandibular canal to lingual cortex in three skeletal groups was $3.63 \pm 0.97 \mathrm{~mm}$ at furcation site of first molar tooth. The distance from mandibular canal to buccal cortex was $6.00 \pm 1.1 \mathrm{~mm}$ at furcation site of first molar and the distance from mandibular canal to lingual cortex was $4.09 \pm$ $1.34 \mathrm{~mm}$ at distal of second molar tooth. The distance from mandibular canal to buccal cortex was $5.72 \pm 1.38 \mathrm{~mm}$ at distal of second molar tooth. Kunte et al. [16] measured the thickness of buccal and lingual plates in the posterior region and showed that the thickness of buccal and lingual plates increased from the second premolar towards the second molar region. Temple et al. [17] reported an increase in the thickness of buccal plate from the anterior towards posterior region. Hallikainen et al. [18] by using the CT reported that the buccolingual thickness of mandible was significantly greater in patients with mandibular prognathism compared to that in patients with mandibular retrognathism. They also stated that the mandibular canal in patients with retrognathism was located in a more lingual position compared to that in patients with prognathism. In the study by Yun et al. [15] the buccolingual thickness of mandible in patients with prognathism was smaller than skeletal class I malocclusion s, and mandibular canal in patients with prognathism was located in a more lingual position compared to skeletal class I . Our results are in agreement with the results of Hallikainen et al.[18] as the buccolingual thickness of the mandible in patients with prognathism is greater than that in normal individuals and those with retrognathism. Also, the mandibular canal in patients with mandibular retrognathism was closer to the lingual plate compared to skeletal class I and those with prognathism. However, in contrast to Hallikainen et al. [18], these differences were not statistically significant in our study.

In our study, the mean thickness of ramus were $5.80 \pm 1.21 \mathrm{~mm}, 5.73 \pm 1.13 \mathrm{~mm}$ and 5.1 $\pm 61.19 \mathrm{~mm}$ in skeletal class I, skeletal class II and skeletal class III patients, respectively. Almeida et al. [19] used CT to measure the ramus thickness at the site of lingula and reported the ramus thickness to be $7.19 \pm 0.91 \mathrm{~mm}, 7.15 \pm$ $0.96 \mathrm{~mm}$, and $7.30 \pm 0.82 \mathrm{~mm}$ in skeletal class I, skeletal class II and skeletal class III patients, respectively. They used ANB angle and the Wits appraisal for classification of malocclusion; thus, maxillary disorders can also affect the results; whereas, in our study, only the mandibular deficiency was considered. Differences between the results of two studies may be due to the difference in measurement site of ramus thickness. In our study, ramus thickness was measured $1 \mathrm{~cm}$ below the lingula while Almeida et al. measured the ramus thickness at the lingula site. Moreover, the imaging modality was different since we used CBCT and they used CT. The accuracy of CBCT is higher than CT and however, the measurement location and classification of skeletal deficiency are the same, but our results are closer to the actual values. Ribeiro et al. [20] by using CT reported that the ramus width in patients with retrognathism was greater than that in patients with prognathism. Noleto et al. [21] used CT and reported that the ramus width in patients with retrognathism was greater than that in patients with prognathism. In our study, the ramus width was not significantly different among the three groups.

In our study, the mean distance from the mandibular foramen to the anterior border, posterior border, sigmoid notch and inferior border of ramus in the three groups were 15.19 $\pm 1.81 \mathrm{~mm}, 12.47 \pm 2.03 \mathrm{~mm}, 19.25 \pm 3.09$ $\mathrm{mm}, 28.44 \pm 4.6 \mathrm{~mm}$, respectively. In a study by Padamavathi et al, [22] on dry skulls, the distance from the mandibular foramen to the anterior border, posterior border, sigmoid notch and 
inferior border of ramus were $16.9 \pm 2.7 \mathrm{~mm}, 11.2$ $\pm 9.2 \mathrm{~mm}, 22.3 \pm 1.2 \mathrm{~mm}$ and $24.9 \pm 3.3 \mathrm{~mm}$, respectively. Oguz et al, [11] also assessed the mandibular foramen on dry skulls and reported that the distance from the mandibular foramen to the inferior border, posterior border, sigmoid notch and inferior border of mandible were $17.9 \mathrm{~mm}, 14.09 \mathrm{~mm}, 22.37 \mathrm{~mm}$ and $30.97 \mathrm{~mm}$, respectively. Padamavathi et al. [22], and Oguz et al.[11] did not mention the normal position, prognathism or retrognathism of the mandible in their studies and they reported combination of measurements made on mandibles with different skeletal patterns. Moreover, difference in values may be due to different methods of mandibular foramen assessment in the afore-mentioned two studies and our study; naturally, the anatomy of the mandibular foramen may vary in different groups.

In our study, the mean ramus height was $47.70 \pm 4.65 \mathrm{~mm}$ in the three skeletal groups; this value in the study by Padmavathi et al [22] was reported as $47.7 \pm 6 \mathrm{~mm}$. In a study by Aarabi et al, [5 ]on the anatomy of mandible in bad split patients compared to those without bad splits, ramus height was $40.2 \pm 06.44 \mathrm{~mm}$ in the bad split and $47.6 \pm 05.33 \mathrm{~mm}$ in the group without bad splits. Different assessment method and history of surgical procedure can explain the final results but in general, ramus height decreases in skeletal class II and class III patients compared to skeletal class I [2].

In our study, the mean length of mandible body in skeletal class I, class II and class III patients were $88.50 \pm 5.32 \mathrm{~mm}, 82.20 \pm 3.04 \mathrm{~mm}$ and $92.17 \pm 6.7 \mathrm{~mm}$, respectively. In skeletal class II patients, the mandible body length decreases while the gonial angle increases compared to skeletal class I individuals. In skeletal class III patients, mandible body length and size of gonial angle increase.

\section{CONCLUSION}

- Distance from the mental foramen to the apex of second premolar tooth, buccolingual thickness of the mandible, length of mandible body and ramus width were not significantly different among the three groups of class I, class II and class III patients.

- Ramus height was smaller in skeletal class II patients compared to skeletal class I malocclusion .

- Ramus height was not significantly different in skeletal class III and class I.

- Mandible body length was greater in skeletal class III patients compared to class I. This value class I was greater than that in skeletal class II patients.

- Distance from the mandibular canal to the anterior border of ramus in skeletal class I malocclusion was greater than that in skeletal class III patients. Skeletal class I and class II patients were not significantly different in this respect.

- Distance from the mandibular foramen to the sigmoid notch in skeletal class I was greater than that in skeletal class II patients. skeletal class I malocclusion and class III patients were not significantly different in this respect.

\section{REFERENCES}

1. Kim HJ, Lee HY, Chung IH, Cha IH, Yi CK. Mandibular anatomy related to sagittal split ramus osteotomy in Koreans. Yonsei Med J. 1997 Feb;38(1):1925. doi: 10.3349/ymj.1997.38.1.19

2. Bishara SE, Athanasiou AE. Textbook of orthodontics. Philadelphia,USA: Saunders; 2001.

3. Lee HJ, Lee S, Lee EJ, Song IJ, Kang BC, Lee JS, et al. A comparative study of the deviation of the menton on posteroanterior cephalograms and threedimensional computed tomography.. Imaging Sci Dent. 2016 Mar;46(1):33-8. doi: 10.5624/isd.2016.46.1.33.

4. Kim MS, Lee EJ, Song IJ, Lee JS, Kang BC, Yoon SJ. The location of midfacial landmarks according to the method of establishing the midsagittal reference plane in three-dimensional computed tomography analysis of facial asymmetry. Imaging Sci Dent. 2015 Dec;45(4):227-32. doi: 10.5624/ isd.2015.45.4.227. 
5. Shokri A, Miresmaeili A, Farhadian N, Falah-Kooshki S, Amini P,Mollaie N. Effect of changing the head position on accuracy of transverse measurements of the maxillofacial region made on cone beam computed tomography and conventional posterior-anterior cephalograms. Dentomaxillofac Radiol. 2017 Jul;46(5):20160180. doi:10.1259/dmfr.20160180

6. de Azevedo Vaz SL, Vasconcelos TV, Neves FS, de Freitas DQ, Haiter-Neto F. Influence of cone-beam computed tomography enhancement filters on diagnosis of simulated external root resorption. J Endod. 2012 Mar 31;38(3):305-8. doi:10.1016/j.joen.2011.10.012

7. Quereshy FA, Savell TA, Palomo JM. Applications of cone beam computed tomography in the practice of oral and maxillofacial surgery. $\mathrm{J}$ Oral maxillofacial Surg. 2008 Apr 1;66(4):791-6. doi: 10.1016/j.joms.2007.11.018.

8. Farman AG, Scarfe WC. The basics of maxillofacial cone beam computed tomography. Semin Orthod. 2009;15(1):2-13.

9. Budhiraja V, Rastogi R, Lalwani R, Goel P, Bose SC. Study of position, shape, and size of mental foramen utilizing various parameters in dry adult human mandibles from north India. ISRN Anat. 2012 Dec 17;2013:961429. doi: $10.5402 / 2013 / 961429$

10. Ghaffari R, Hosseinzade A, Zarabi H, Kazemi M. Mandibular dimensional changes with aging in three dimensional computed tomographic study in 2 to 50 Year old men and women. J Dentomaxillofac Radiol Pathol Surg 2013; 2(1):7-122. doi: 10.18869/acadpub.3dj.2.1.2.

11. Oguz 0, Bozkir MG. Evaluation of location of mandibular and mental foramina in dry, young, adult human male, dentulous mandibles. West Indian Med J. 2002 Mar;51(1):14-6

12. Voljevica A, TalovićE, Hasanović A. Morphological and morphometric analysis of the shape,position, number and size of mental foramen on human mandibles. Acta Med Acad. 2015;44(1):31-8.

13. Kane AA, Lo LJ, Chen YR, Hsu KH, Noordhoff MS. The course of the inferior alveolar nerve in the normal human mandibular ramus and in patients presenting for cosmetic reduction of the mandibular angles. Plast Reconstr Surg. 2000 0ct;106(5):1162-74; discussion 1175-6. doi: 10.1097/00006534200010000-00029.
14. Sekerci AE, Sahman H. Cone beam computed tomographic analyses of the position and course of the mandibular canal: relevance to the sagittal split ramus osteotomy. BioMed research international. 2014;2014:945671. doi: 10.1155/2014/945671.

15. Yu IH, Wong YK. Evaluation of mandibular anatomy related to sagittal split ramus osteotomy using 3-dimensional computed tomography scan images. Int J Oral Maxillofac Surg. 2008 Jun;37(6):521-8. doi: 10.1016/j. ijom.2008.03.003

16. Kunte VR, Bhoosreddy AR, Bhoosreddy SA, Pandharbale AA, Shinde MR, Ahire BS. Alveolar bone dimensions of mandibular posterior teeth using cone beam computed tomography. JContemp Dent. 2016;6(1):9-14.

17. Temple KE, Schoolfield J, Noujeim ME, Huynh-Ba G, Lasho DJ, Mealey BL. A cone beam computed tomography (CBCT) study of buccal plate thickness of the maxillary and mandibular posterior dentition. Clin Oral Implants Res. 2016 Sep;27(9):1072-8. doi:10.1111/clr.12688.

18. Hallikainen D, lizuka $T$, Lindqvist C. Cross-sectional tomography in evaluation of patients undergoing sagittal split osteotomy. J Oral Maxillofac Surg. 1992 Dec;50(12):1269-73. doi:10.1016/0278-2391(92)90225-0.

19. Costa PB, Bittencourt MA, Rebello IM. Assessment of mandibular ramus thickness in Afro-Brazilian subjects using computed tomography. Eur J Gen Dent. 2014 May 1;3(2):140-5. doi:10.4103/2278-9626.134842

20. Ribeiro DP, Gandelmann IH, Medeiros PJ. Comparison of mandibular rami width in patients with prognathism and retrognathia. J Oral Maxillofac Surg. 2006 0ct;64(10):1506-9. doi: 10.1016/j.joms.2006.07.001

21. Noleto JW, Marchiori E, Da Silveira HM. Evaluation of mandibular ramus morphology using computed tomography in patients with mandibular prognathism and retrognathia: relevance to the sagittal split ramus osteotomy. J Oral Maxillofac Surg. 2010 Aug;68(8):1788-94. doi:10.1016/j. joms.2009.12.028.

22. Padmavathi G, Tiwari S, Varalakshmi KL, Roopashree R. An anatomical study of mandibular and accessory mandibular foramen in dry adult human mandibles of south Indian origin. IOSR J Dent Med Sci. 2014;13(4):83-8. doi $10.9790 / 0853-13428388$

\section{Abbas Shokri \\ (Corresponding address)}

Department of Oral and Maxillofacial Radiology, Dental School, Hamadan University of

Medical Sciences, Hamadan, Iran.

Date submitted: 2020 Aug 28

Email: Dr.a.shokri@gmail.com 